\title{
NUMERICALLY SIMULATING THE EFFECT OF REBAR DISTRIBUTION ON THE CONCRETE FLEXURAL STRENGTH
}

\author{
Wael A. Salah ${ }^{1}$, Osama S. Hussien ${ }^{2}$ \\ ${ }^{1}$ PhD, Civil Engineering Department, Faculty of Engineering, Al-AzharUniersity, Egypt \\ ${ }^{2}$ PhD, Civil Engineering Department, Faculty of Engineering, Al-AzharUniersity, Egypt
}

\begin{abstract}
This paper presents a developed three dimensional (3D) finite element (FE) model, using ABAQUS software, to explore the effect of the reinforcing rebar distribution on the flexural strength for exterior beam-column joints. The results of the experimental tests conducted by Rekha S. P. et al. [1], are used to validate the results of the developed FE model. Three exterior beam-column joint specimens, have been experimentally investigated under the effect of static loading by Rekha S. P. et al. [1]. Each of the tested specimen has the same reinforcement ratio but with varying bar diameters to allow for variable distribution of reinforcing rebar. Three more beam-column joint specimens have been prepared exactly as the first three specimens but with beam of closer stirrups spacing. The six specimens have been statically loaded reaching the failure load and hence the flexural strength was determined for each. Six FE models of exterior beam-column joint are created simulating the former experimentally tested concrete joints. The developed geometrically and material nonlinear $3 D$ model is able to trace the load-displacement path for all the tested concrete joints with adequate accuracy.
\end{abstract}

Keywords:Beam-Column Joint, FE, Modeling, Rebar, Flexural Strength.

\section{INTRODUCTION}

The intersection of beam and column is called a joint or connection. The performance of beam-column joints have long been conceded as an influential ingredient that impacts the general performance of reinforced concrete framed structures subjected to large lateral loads. The reversal of forces in beam-column joints during earthquakes may cause distress and often failure, when not designed and detailed properly. However, the current study is focused on the behavior of the concrete beam-column joint under the effect of monotonic loading.

Multiple approaches in modelling beam-column joint response have been proposed through earlier researches with using experimental data to calibrate these models. At the early stage, the inelastic response of the concrete frames was introduced as the response of a plastic hinge within beamcolumn line element [2], [3], [4], [5]. Later on, a rotational spring element of zero-length has been used to connect beam and column elements as proposed by El-Metwally and Chen [6], Alath and Kunnath [7]. Three dimensional nonlinear FE has been developed by Nagai et al. [8] to simulate the response of high strength concrete beamcolumn joint exposed to biaxial monotonic loading. Apart from these relatively simplified models, Eligehausen et al. [9] and Sharma et al. [10] have proposed a detailed FE modeling for fracture in quasi-brittle materials.

\section{EXPERIMENTAL TESTS}

\subsection{Beam-Column JointPresentation}

Six specimens of exterior beam-column joints were prepared and tested by Rekha S Patel et al. [1]. The experimental tests have aimed to study the effect of varying diameter of the tensile reinforcement bars in beam and spacing of stirrups on the flexural strength. The 28 day compressive strength of $150 \times 150 \mathrm{~mm}$ cube was found to be $42.85 \mathrm{MPa}$.

The cross section for both of column and beam was $230 \times$ $160 \mathrm{~mm}$. The column length is $1000 \mathrm{~mm}$ while the beam length was $600 \mathrm{~mm}$ measured from the column's face. The columns were reinforced with 4 bars of $16 \mathrm{~mm}$ diameter and stirrups of $8 \mathrm{~mm}$ diameter with $160 \mathrm{~mm}$ c/c spacing. 6 of 8 $\mathrm{mm}$ diameter, 4 of $10 \mathrm{~mm}$ diameter, and 3 of $12 \mathrm{~mm}$ diameter bars were provided at the tensile face for beams in specimens BCJ1, BCJ2, and BCJ3 respectively. 2 bars of 8 $\mathrm{mm}$ diameter were used in the compressive face for all tested beam-column specimens. In the first three specimens, the spacing of the shear reinforcement was set aside $150 \mathrm{~mm}$ $\mathrm{c} / \mathrm{c}$ while in the left three specimens namely BCJ4, BCJ5, and BCJ6, the stirrups spacing was $100 \mathrm{~mm} \mathrm{c/c}$ as detailed in Fig-1.

\subsection{Experimental Setup and Loading Procedure}

The beam-column joint specimens have been tested using a loading cell of $100 \mathrm{kN}$ loading capacity. Each prepared specimen was affirmed where the bottom end of the column was restrained against both the vertical and lateral translations. On the other hand, the top end of the column was only laterally restrained. $130 \mathrm{kN}$ axial load was applied on the top end of the column using a hydraulic jack of 500 $\mathrm{kN}$ capacity. A point load was applied to the beam at a distance of $100 \mathrm{~mm}$ from the beam end. Dial gauge was used to measure the beam tip deflection at every load increment of $2 \mathrm{kN}$. The setup of the test rig is shown in Fig2. 
a)

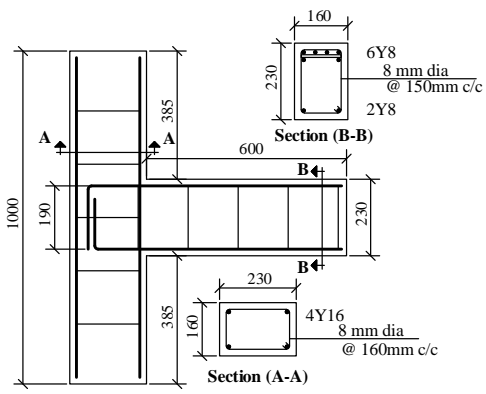

b)

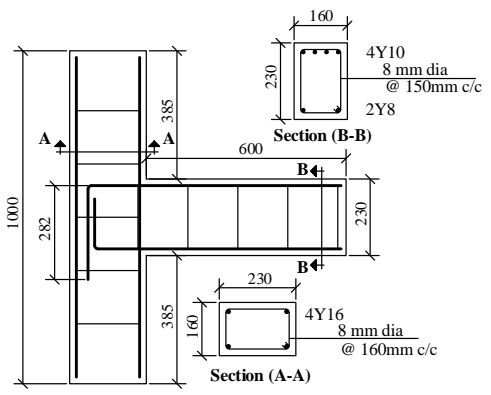

c)

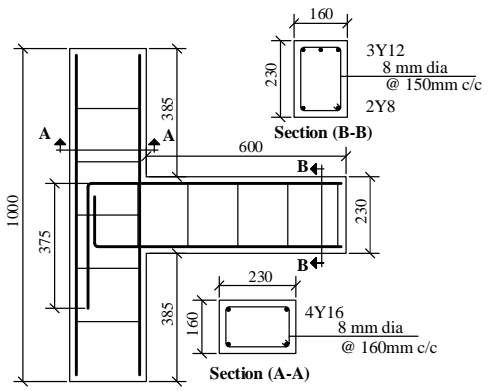

d)

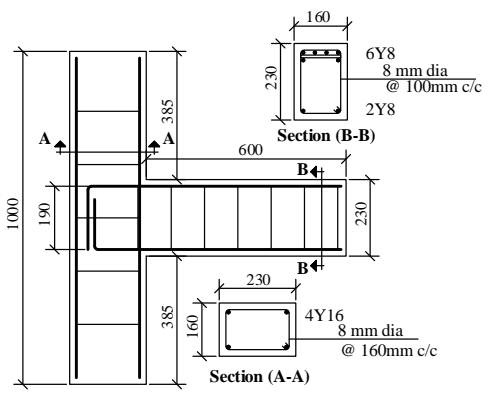

e)

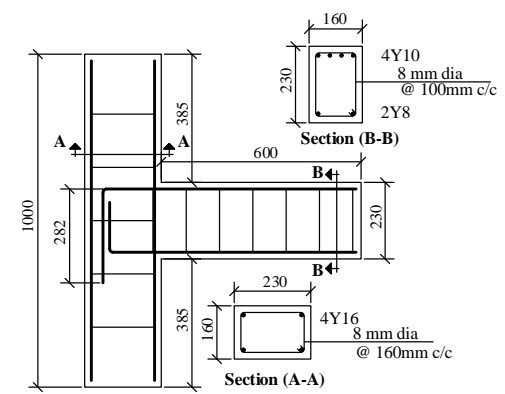

f)

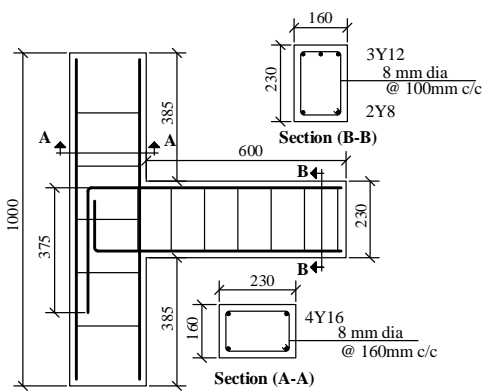

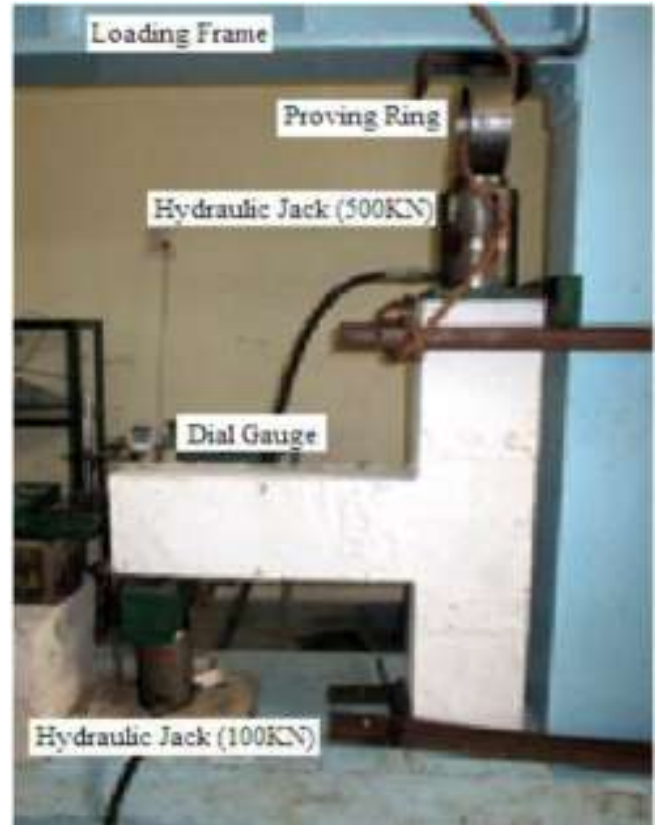

Fig- 2:Test rig setup [1]

Each of the tested specimens was loaded up to failure. The applied load values corresponding to the first crack and the ultimate load were recorded besides the ultimate deflection. The experimental results have proved that, the concrete beam provided with constant area of reinforcing bars but with a smaller bar diameter, in the tension side could carry a relatively higher ultimate load. Moreover, reducing the stirrups spacing has resulted in a greater load carrying capacity and a higher ductility.

\section{NUMERICAL MODELLING}

\subsection{Introduction}

FE method is a numerical analysis for attaining approximate solutions to an extensive diversity of engineering problems. This has flourished concurrently with growing use of highspeed digital computers and with the evolution in numerical methods for engineering analysis. In consequence of its variety and flexibility as analysis tool, it is receives much attention in engineering field and in industry. FE analysis is a helpful technique for resolving structures of complex geometry, high nonlinear materials, and intricate boundary conditions. This method can issue extensive and authentic results if it is used appropriately. Moreover the FE analysis is much cheaper than the full-scale tests. To achieve prosperous results, a precise model simulating the real structures should be considered.

Since the purpose of this study is to better simulating the behavior of the concrete beam-column joint under the effect of monotonic loading, a detailed 3D FE model has been developed. The proved model is able to accurately capture the performance of beam-column joint under the effect of static loading.

Fig- 1:Specimens of beam-column joint reinforcement details [1] 


\subsection{Discrete Element}

The concrete beam-column joint is modelled using eight node continuum hexahedral brick elements with reduced integration, C3D8R, available in ABAQUS code. Such eligible eight node brick element is able to simulate the behavior of nonlinear static and dynamic analysis and allows for finite strain and rotation in large displacement analysis as well. The longitudinal and confinement reinforcement bars are modelled as a truss element T3D2 available in ABAQUS. The embedded element option is used to the represent the bond relation between reinforcement bars and concrete. Embedded element technique presented a good performance tool that facilitates modelling of concrete-reinforcement rebar relation under monotonic loading. Such embedded elements option allows to use varying mesh sizes for both of concrete and reinforcement rebar. Fig-3 shows the element discretization for both of the concrete block joint a) and the reinforcing bars b) as well.

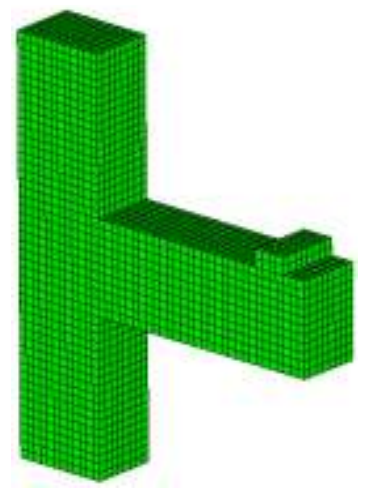

a) FE mesh of concrete beamcolumn joint

Fig- 3: Discretized elements of the FE model

\subsection{Material Modelling}

\subsubsection{Steel Reinforcing Rebar Constitutive Model}

Idealized elastic perfectly plastic constitutive model, shown in Fig-4, is considered to represent the behavior of the steel reinforcing rebar. The linear elastic behavior at low strain values is defined through introducing the Young's modulus to the software code. The nonlinear behavior initiates corresponding to higher strain values. Before achieving the yield stress, the developed deformation produces only elastic strains, which is entirely recovered when the applied load is removed. As soon as the rebar stress transcends the yield stress, plastic deformation initiates regarding any further deformations. The yield stress for longitudinal bars and confinement bars is taken as $500 \mathrm{MPa}$ with $200000 \mathrm{MPa}$ modulus of elasticity and 0.3 Poisson' ratio.

\subsubsection{Concrete Constitutive Model}

The concrete damaged plasticity (CDP) available in ABAQUS code is used to represent the concrete material. The concrete inelastic behavior is modelled using the connotation of isotropic damaged plasticity together withisotropic tensile and compressive plasticity included in the CDP constitutive model. Such model is proposed mostly for the analysis of concrete structures exposed to monotonic, cyclic, and dynamic loads. CDP uses stress-strain to relate parameters for relative concrete damage in compression or in tension. After achieving the yield stress in a simple plasticity model, the residual plastic strain remains after removing the applied load by repercussion function of the concrete modulus of elasticity. CDP parameters adjust the repercussion function to encompass the damage effects as shown in Fig- 5. CDP model takes into account the effect of cyclic loading since a retrieval factor could be assigned to consider the total magnitude of the reverse loading strength available after achieving the damage.

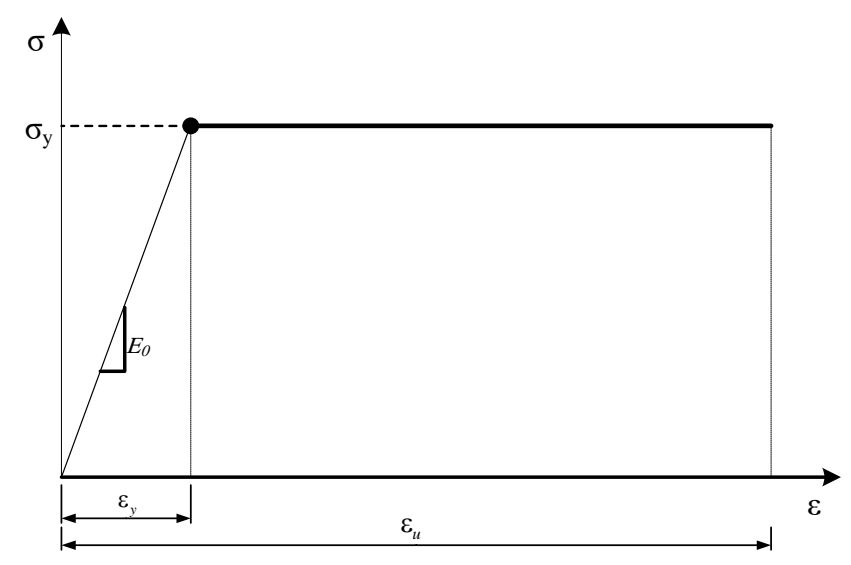

Fig- 4: Elastic perfectly plastic constitutive model for steel reinforcing bars

Regarding uniaxial tension, the stress-strain relation starts linearly till achieving the failure tension value $\sigma_{t 0}$. After the circumstance of the concrete failure strain, the softening stress-strain response containing strain localization in the concrete structures, is used to represent the developing of concrete micro cracks. On the opposite, the concrete response is linear under the effect of uniaxial compression till achieving the initial yield value $\sigma_{c 0}$. The response is identified in the plastic reign by the strain hardening proceeded by softening of strain after achieving the ultimate stress $\sigma_{\mathrm{cu}}$, as presented in Fig-5 b). Although such representation is relatively simplified, it can capture the main concrete characteristics. Thus, concrete stress during unloading state at any point on the strain softening branch of the stress-strain curve, can be determined by:

$$
\begin{aligned}
& \sigma_{t}=E_{0}\left(\varepsilon_{t}-\tilde{\varepsilon}_{t}^{p l}\right)\left(1-d_{t}\right) \\
& \sigma_{c}=E_{0}\left(\varepsilon_{c}-\tilde{\varepsilon}_{c}^{p l}\right)\left(1-d_{c}\right)
\end{aligned}
$$

Where $E_{0}$ is the initial concrete modulus of elasticity. $\varepsilon_{t}, \varepsilon_{c}$ are the total tensile and compressive strains respectively. $\tilde{\varepsilon}_{t}^{p l}, \tilde{\varepsilon}_{c}^{p l}$ are the equivalent tensile and compressive plastic strains respectively. $d_{t}, d_{c}$ are the damage variables that characterize the degradation of the concrete elastic stiffness. The damage variables may have values from zero to one, representing the undamaged 
material and the entire loss of strength respectively. The plastic strain, temperature, and field variables are the parameters that impact the concrete damage variables:

$$
\begin{aligned}
& d_{t}=d_{t}\left(\tilde{\varepsilon}_{t}^{p l}, \theta, f_{i}\right) ; 0 \leq d_{t} \leq 1 \\
& d_{c}=d_{c}\left(\tilde{\varepsilon}_{c}^{p l}, \theta, f_{i}\right) ; 0 \leq d_{c} \leq 1
\end{aligned}
$$

Where $\theta$ is the temperature and $f_{i},(i=1,2, \ldots .$.$) are other$ predefined variables.

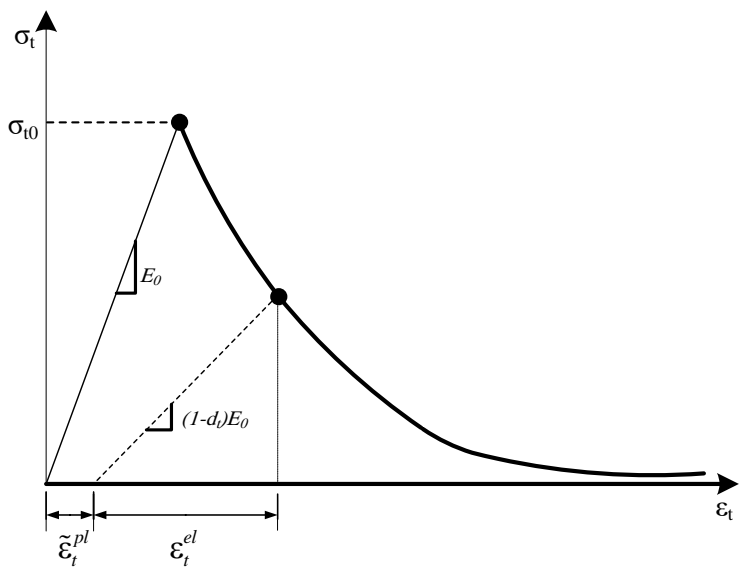

a) Concrete response under uniaxial loading in tension

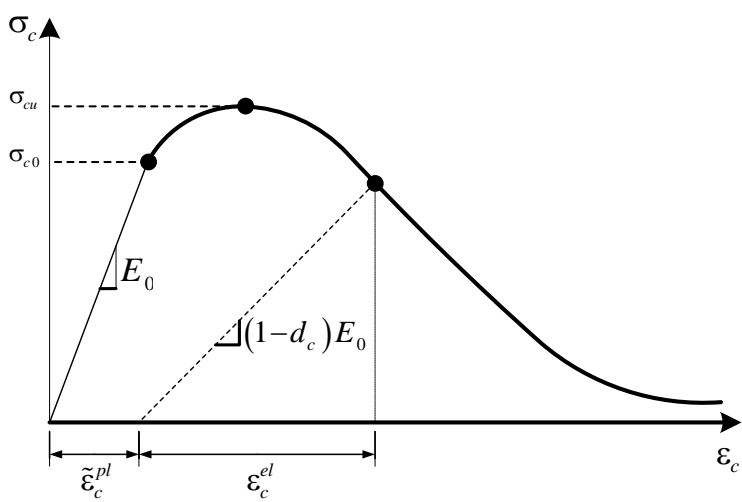

b) Concrete response under uniaxial loading in compression

Fig- 5: Concrete response under uniaxial loading [11]

The effective tensile and compressive concrete stresses are determined by:

$$
\begin{aligned}
& \bar{\sigma}_{t}=\frac{\sigma_{t}}{1-d_{t}}=E_{0}\left(\varepsilon_{t}-\tilde{\varepsilon}_{t}^{p l}\right) \\
& \bar{\sigma}_{c}=\frac{\sigma_{c}}{1-d_{c}}=E_{0}\left(\varepsilon_{c}-\tilde{\varepsilon}_{c}^{p l}\right)
\end{aligned}
$$

The tension stiffening that enables for determining the cracked concrete strain softening behavior, is used to model the interaction relation between rebar and concrete. The post-failure stress-strain relationship may identify the concrete tension stiffening or it could be characterized by applying the fracture energy cracking criterion.In general, the post-failure stress of the reinforced concrete is expressed as a function of cracking strain $\tilde{\varepsilon}_{t}^{c k}$ according to the specification of the post-failure characteristics.

The undamaged elastic strain subtracted from the total strain, results in the cracking strain;

$$
\tilde{\varepsilon}_{t}^{c k}=\varepsilon_{t}-\varepsilon_{0 t}^{e l}
$$

where $\varepsilon_{0 t}^{e l}=\frac{\sigma_{t}}{E_{0}}$

As depicted in Fig-6, tension stiffening parameters are providedas a function of crack strain, $\tilde{\varepsilon}_{t}^{c k}$. The parameters are introducedusing tensile damage relation when unloading parameters are obtainable. The crack strain values are automatically transformed to plastic strain values using the relationship;

$$
\tilde{\varepsilon}_{t}^{p l}=\tilde{\varepsilon}_{t}^{c k}-\frac{d_{t}}{\left(1-d_{t}\right)} \frac{\sigma_{t}}{E_{0}}
$$

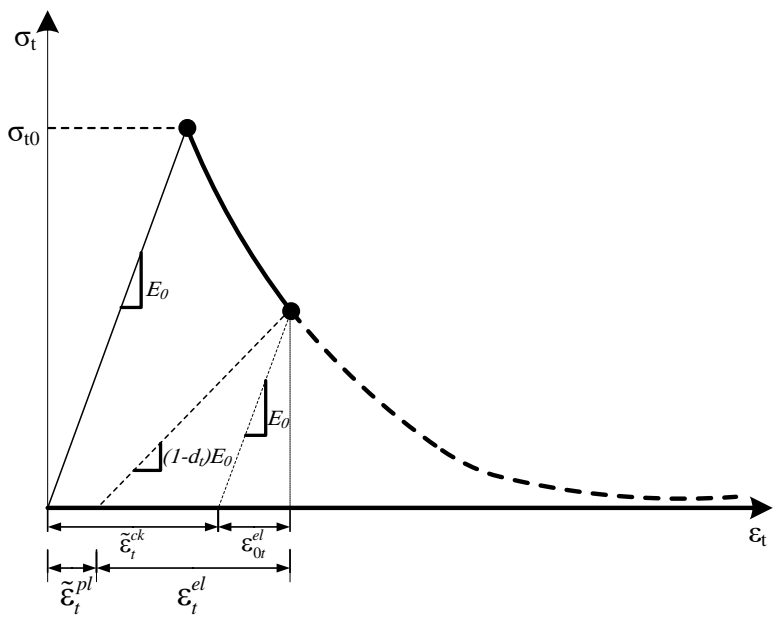

Fig- 6: Tension stiffening data

The interaction between the rebar and the concrete have a propensity to bring down the mesh sensitivity, in condition that a proper quantity of tension stiffening is provided to the FE model to characterize such concrete-rebar interrelation. The response of the tension stiffening depends on some factors as the bond quality between the rebar and the concrete, the reinforcement density, the rebar diameter relative to the size of the concrete aggregate, and the mesh size. The strain softening model could be assumed such that the stress to be degraded linearly from failure stress to zero at a correspondence strain of about ten times the strain at failure. Hence in the tension stiffening, the stress reaches to zero at a correspondence strain of $10^{-3}$ since in standard concretes, the typical failure strain is $10^{-4}$. A precise calibration is required before using this parameter for any different case.

The brittle behavior of the concrete response is introduced as a stress-displacement rather than a stress-strain to overcome the mesh sensitivity. Most of the tensile stress is to be dropped across the open cracks for any concrete specimen exposed to tension force.The crack length is to be 
estimated initially considering the crack opening width. The length of the specimen does not affect the crack opening. The fracture energy of the cracking model could be evoked by providing the stresses of the post-failure relating to cracking displacement as presented in Fig-7.

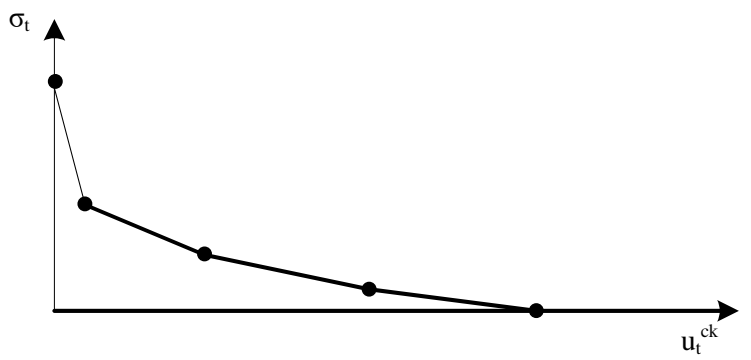

Fig- 7: Post-failure stress-strain curve [11]

The failure stress, $\sigma_{t 0}$, could be provided as a function of the related fracture energy, $G_{f}$, since the fracture energy can be expressed as a material property. After cracking, a linear strength loss is proposed in this model. Fig- 8 presents the linear relation between the failure stress and the corresponded fracture energy.

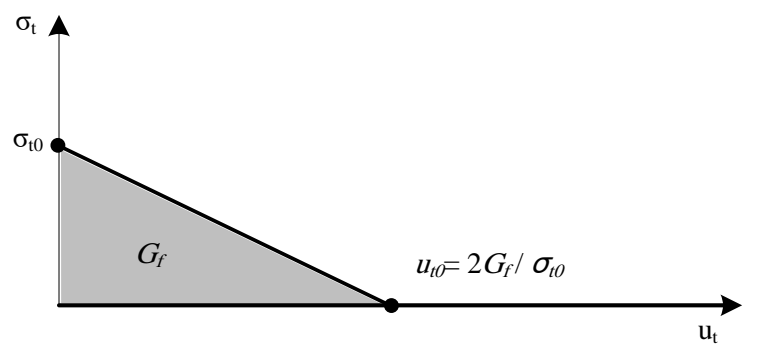

Fig- 8: Relationship between Post-failure stress and fracture energy [11]

At a total loss of strength, the cracking displacement could be expressed as:

$$
u_{t 0}=2 G_{f} / \sigma_{t 0}
$$

The fracture energy $G_{f}$ values range from $40 \mathrm{~N} / \mathrm{m}$ to 120 $\mathrm{N} / \mathrm{mto}$ be assigned to the concrete of compressive strengths range from $20 \mathrm{MPa}$ to $40 \mathrm{MPa}$ respectively. The values of cracking displacement are transformed automatically in ABAQUS code to values of plastic displacement employing the tensile damage parameter, $d_{t}$, as following:

$$
u_{t}^{p l}=u_{t}^{c k}-\frac{d_{t}}{\left(1-d_{t}\right)} \frac{\sigma_{t} l_{0}}{E_{0}}
$$

where $l_{0}$ is the specimen length which is assumed to be a unit length, $l_{0}=1$

The data of compressive stress are introduced as a function of inelastic strain, $\tilde{\varepsilon}_{c}^{i n}$. The compressive stress and strain should have positive values. The strain-softening reign could be employed to draw the stress-strain relation after the ultimate stress. Inelastic compressive strain, $\tilde{\varepsilon}_{c}^{i n}$, is provided rather than plastic compressive strain, $\tilde{\varepsilon}_{c}^{p l}$, in defining hardening data. Considering the undamaged material, the inelastic compressive strain is calculated by subtracting the elastic strain from the total strain.

$$
\tilde{\varepsilon}_{c}^{i n}=\varepsilon_{c}-\varepsilon_{0 c}^{e l}
$$

where $\varepsilon_{0 c}^{e l}=\frac{\sigma_{c}}{E_{0}}$ as presented in Fig-9.

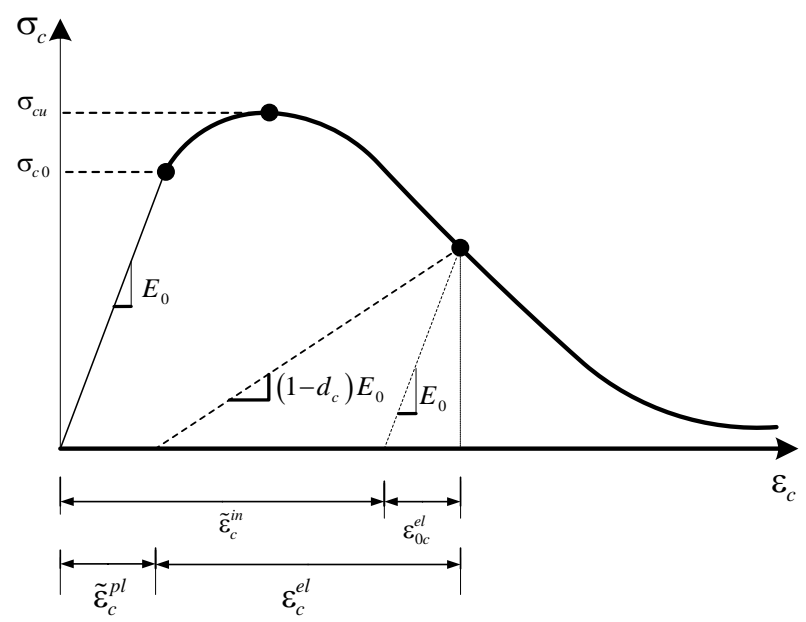

Fig- 9:Concrete performance under axial compressive load [11]

The compressive damage relation, $d_{c}$ vs $\tilde{\varepsilon}_{c}^{i n}$, is used in ABAQUS to define unloading path. Hence, the inelastic strain values are turned into values of plastic strain in ABAQUS by means of the relationship;

$$
\tilde{\varepsilon}_{c}^{p l}=\tilde{\varepsilon}_{c}^{i n}-\frac{d_{c}}{\left(1-d_{c}\right)} \frac{\sigma_{c}}{E_{0}}
$$

The yield condition considered in CDP model, is based on the yield function proposed by Lubliner J. el al. [12] and the modifications proposed by Fenves G.L. and Lee J. [13] to calculate various evolution of strength under tension and compression referring to $p$ as the hydrostatic pressure stress and $q$ as the Mises equivalent effective stress as seen in Fig10.

The coefficient $\alpha$ can be determined from $\sigma_{b 0}$, the biaxial initial yield compressive stress and $\sigma_{c 0}$, uniaxial initial yield compressive stress. Considering the modifications of the Drucker Prager theory, the failure surface in the deviatoric plane does not need to be a circle, and it is also governed for parameter $K_{c}$ as shown inFig-11.

\subsection{Boundary Conditions}

The boundary conditions of the analyzed beam-column joint is provided by restraining the three translation degrees of freedom for the bottom column nodes layer. On the opposite, the top column nodes layer are laterally restrained in both horizontal directions. Analysis are conducted in two simultaneous steps. In the first step, a vertical load of 130 $\mathrm{kN}$ is applied at the center of the top column layer. Next 
step, a vertical displacement is applied gradually at $100 \mathrm{~mm}$ from the beam tip and the force response is evaluated. The vertical displacement is applied to the center of a block of concrete elements as shown inFig-3 that is created and constrained to a rigid body. Such rigid block is provided to avoid any kind of stresses concentration at the point of the load application.

\subsection{FE Results}

The six tested beam-column joints by Rekha S. P. et al. [1] are modelled using ABAQUS code and obtained FE results are compared with those of the tested beam-column joint specimens. The boundary conditions considered result in the bottom column nodes layer restrained in the direction of three translation degrees of freedom while the top column node layer restrained in the direction of the two horizontal translation degrees of freedom. In the FE modelling vertical displacement is applied gradually at $100 \mathrm{~mm}$ from the free beam end and the force response is evaluated. Certain monitoring points are considered for all created meshes in order to measure displacements at these points and also to evaluate the applied load at these joints. Fig-12and Fig-13 present the concrete plastic strains and Mises stresses for the rebar respectively at the end of FE analysis. Concrete plastic strain resulted in the numerical analysis, can draw an approximate map for the concrete cracks that developed in the experimental test. The comparison of the beam-column joint applied load-beam tip displacement is depicted in Fig14. A close agreement, obtained between the FE and the test results presented in the mentioned above figure, provides a strong confidence that other parameters not recorded in the experimental tests could be evaluated directly from the FE models considered.

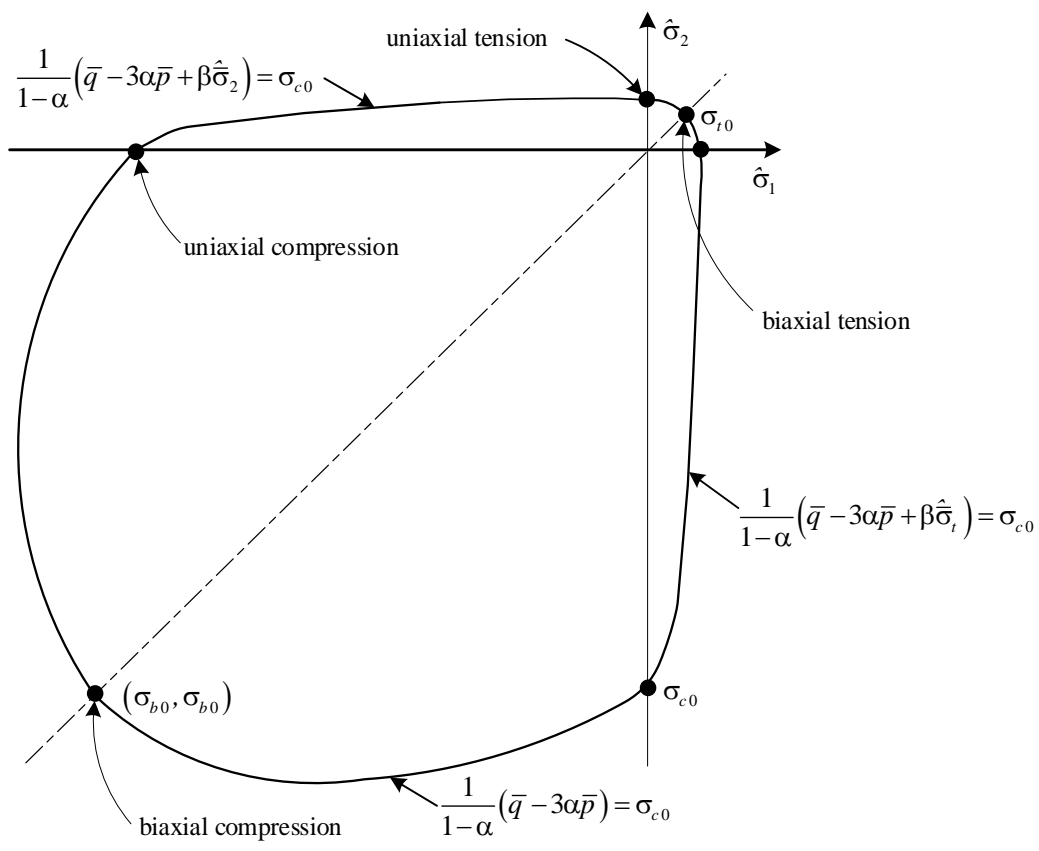

Fig- 10: Typical yield surface for plane stress conditions [11]

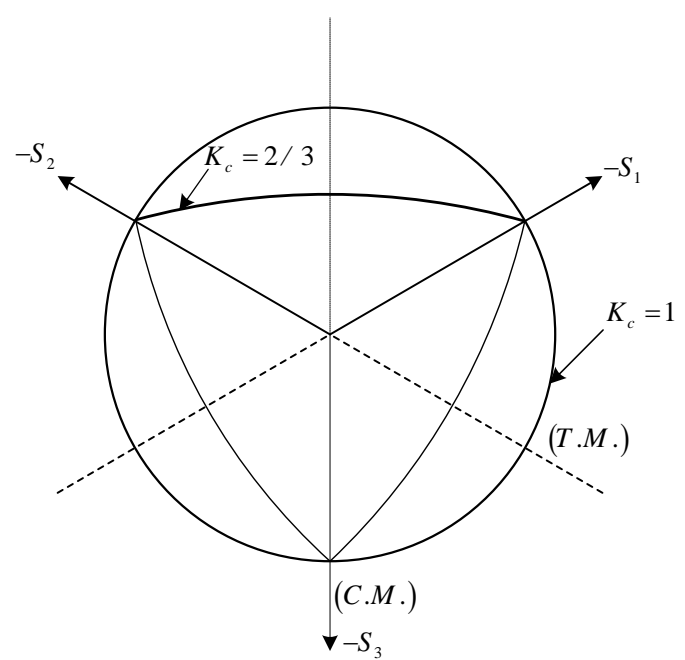

Fig- 11:Typical yield surface on the deviatoric plane [11]

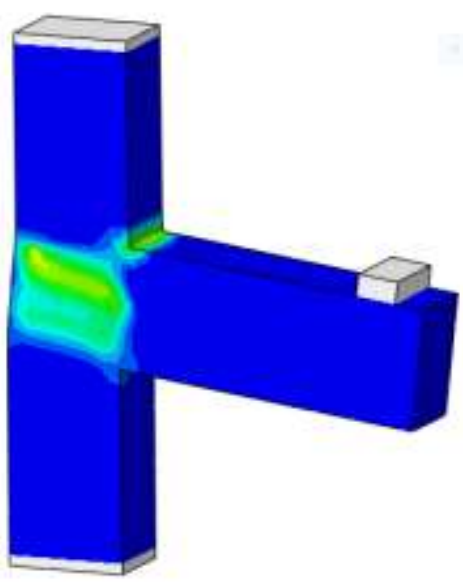

Fig- 12: FE results (Concrete plastic strain) 

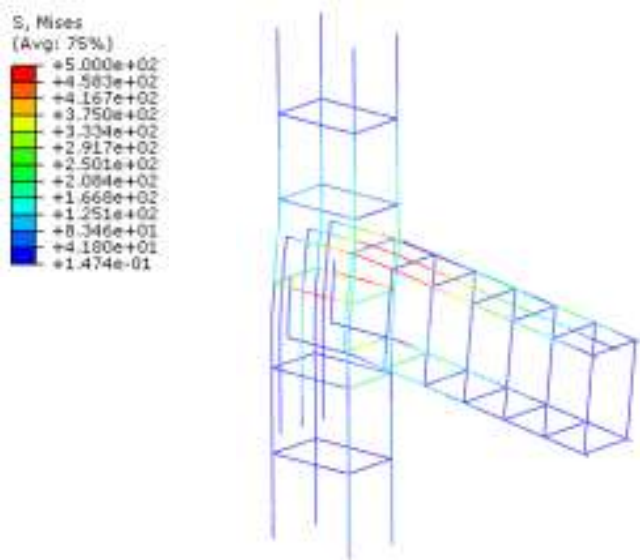

b)

Fig- 13: FE results (Rebar Mises stresses)

\section{CONCLUSIOS}

Numerical investigations are conducted to study the behavior of concrete beam-column joints considering varying distribution of the beam reinforcing bars in addition to varying spacing of beam stirrups. 3D truss elements are used to model the reinforcing bars while 3D brick elements are employed to model the beam-column concrete block. FE results are compared with experimental data. The obtained results show a good agreement between the predicted and measured responses in both the elastic and plastic ranges. This proves that the FE technique is capable of predicting connection response to an acceptable degree of accuracy. The best fitting of the numerical and experimental characteristics given on charts is noticeable at the elastic and beyond the elastic ranges. The developed FE model of beam-column joint can predict with a high degree of accuracy the concrete joint ultimate load. Very close agreements attained between FE and experimental results shown in Fig-14, give a strong confidence that other parameters not considered in the experimental tests could be evaluated directly from the developed FE model.

a) BCJ1

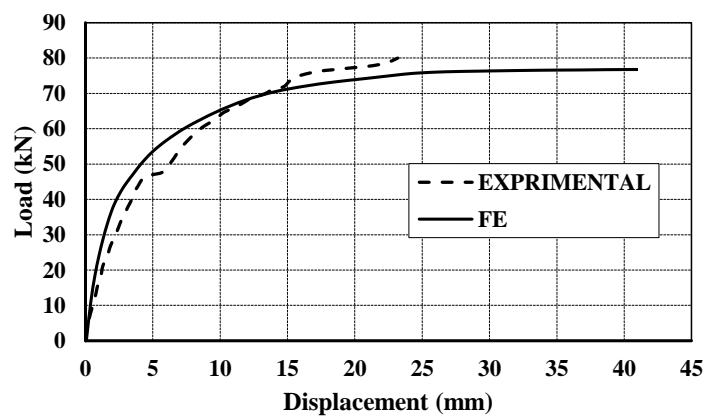

b)BC.J2

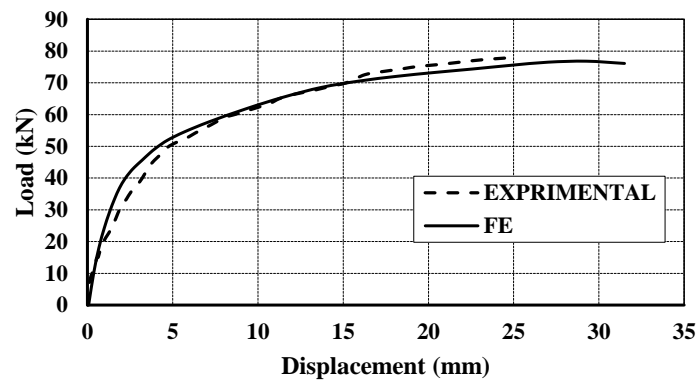

c)BCJ3

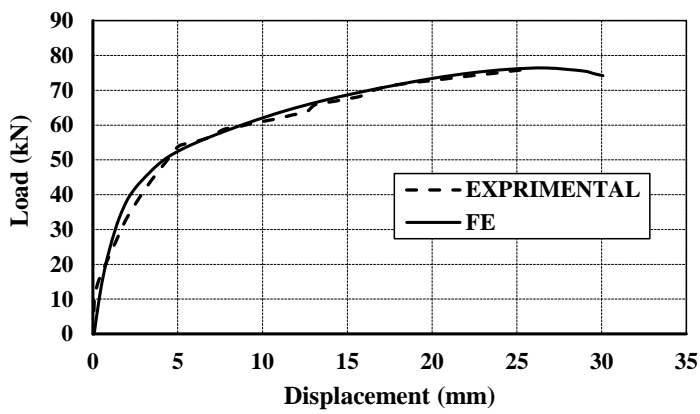

d)BCJ4

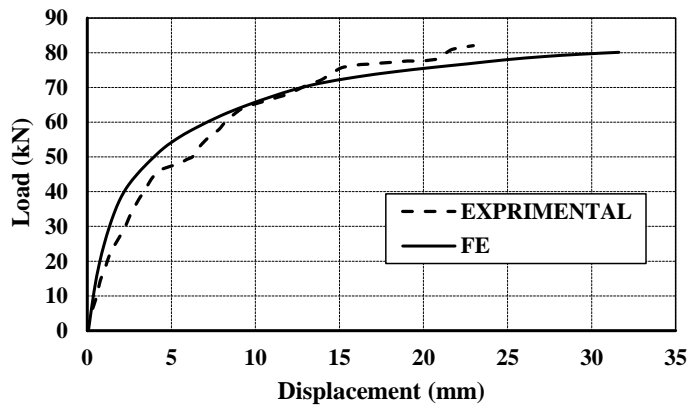

e)BCJ5

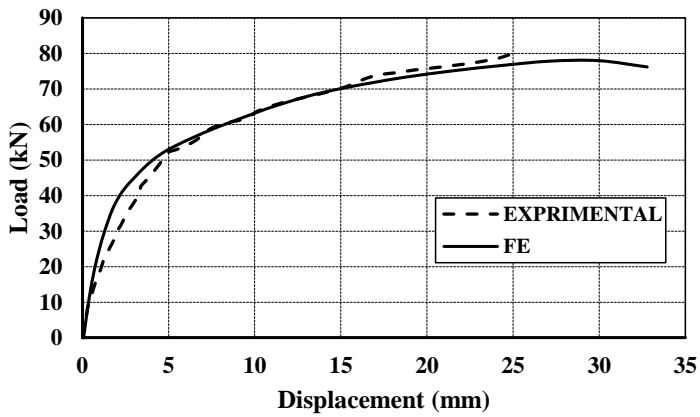

f)BCJ6

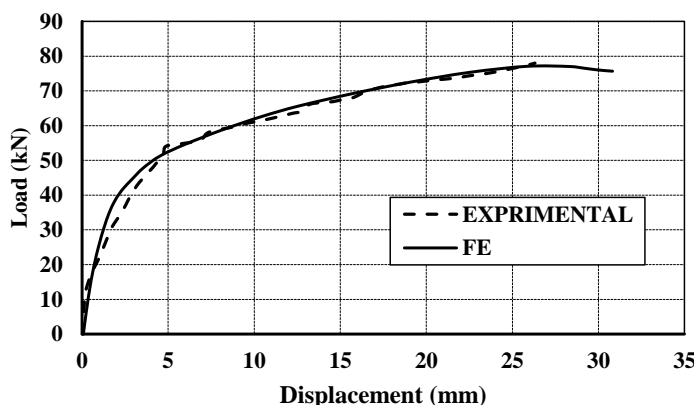

Fig- 14:Load-displacement comparisons between FE and test results 


\section{REFERENCES}

[1] Patel R., Nambiyanna B., Prabhakara R., An experimental study on the effect of diameter of rebar on exterior beam column joint, International Journal of Innovative Research in Science, Engineering and Technology, vol. 4, issue 7, pp. 5984-5992, 2015.

[2] Townsend W.H., Hanson R.D., Hysteresis loops for reinforced concrete beam-column connections, proceedings of $5^{\text {th }}$ World Conference on Earthquake Engineering, vol. I, pp. 1131-1134, 1973.

[3] Otani S., Inelastic analysis of RC frame structures, Journal of the Structural Division, ASCE, vol. 100 (ST7), pp. 1433-1449, 1974.

[4] Anderson J.C., Townsend W.H., Models for RC frames with degrading stiffness, Journal of the Structural Division, ASCE, vol. 103 (ST12), pp. 1433-1449, 1977.

[5] Soleimani D., Popv E.P., Bertero V.V., Nonlinear beam model for RC frame analysis, proceedings of $7^{\text {th }}$ ASCE Conference on Electronic Computation, pp. 483-509, 1979.

[6] El-Metwally S.E., Chen W.F., Moment-Rotation modeling of reinforced concrete beam-column connections, ACI Structural Journal, vol. 85 (4), pp. 384-394, 1988.

[7] Alath S., Kunnath S.K., Modeling inelastic shear deformation in RC beam-column joints, Engineering Mechanics, Proceeding of $10^{\text {th }}$ Conference, University of Colorado at Boulder, Boulder, Colorado, vol. 2, New York, ASCE, pp. 822-825, May 21-24, 1995.

[8] Nagai T., Kashiwazaki T., Noguchi H., Three dimensional nonlinear finite element analysis of RC interior beam-column joints with ultra high-strength materials under bi-directional load, Japan Concrete Institute, Paper No. 476, 1996.

[9] Eligehausen R., Ožbolt J. Genesio G., Hoehler M.S., Pampanin S., Three dimensional modeling of poorly detailed RC frame joints, Proceeding of the Annual NZSEE Conference, Paper No. 23, 2006.

[10] Sharma A., Genesio G., Reddy G.R., Eligehausen R., Nonlinear cyclic analysis using microplane model for concrete and bod slip model for prediction of behavior of non-seismically detailed RCC beam-column joints, Journal of Structural Engineering, vol. 36 (4), pp. 250257, 2009.

[11] Hibbitt, Karlson, and Sorenson, “ABAQUS User's Manual", Version 6.14, Part 1 \& 2, 2014.

[12] Lubliner J., Oliver J., Oller S., Oñate E., A PlasticDamage model for concrete, International Journal of Solids and Structures, vol. 25, pp. 299-329, 1989.

[13] Lee J., Fenves G.L., Plastic-damage model for cyclic loading of concrete structures, Journal of Eng. Mechanics, vol. 124, No.8, pp. 892-900,1998.

\section{BIOGRAPHIES}

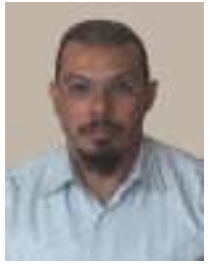

Dr. Wael Salah was born in Egypt in 1972. He received the B.E., M.E. degrees from $\mathrm{Al}$ Azhar University, Egypt, in 1995 and 2000 respectively. He got a special diploma in Earthquake Engineering form International Institute of Seismology and Earthquake Engineering, Tsukuba, Japan in 2002. He received the $\mathrm{Ph} . \mathrm{D}$. degree in Civil Engineering from Warsaw University of Technology, Poland, in 2009. In 1997 he joined the Department of Civil Engineering, Faculty of Engineering, Al Azhar University as a demonstrator and in 2000 he became a lecturer and in 2010 he became an Assistant Professor. He published many papers in the area of steel structures and steel-concrete composite structures. He participated in many international conferences.

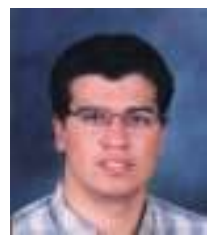

Dr. Osama Hussien was born in Egypt in 1977. He obtained B.E., M.E., and Ph.D. degrees in Civil Engineering from $\mathrm{Al}$ Azhar University, Egypt in 2000, 2004, and 2008 respectively. He joined the Department of Civil Engineering, Faculty of Engineering, AlAzhar University as a demonstrator in 2001 and in 2004 he became a lecturer and he became an Assistant Professor in 2008. He is a member in Egyptian Syndicate of Engineers. He published many articles in the field of structure analysis. He joined more than five private universities as a part time Assistant Professor. 